\title{
A sala de aula nas publicações da Revista História Hoje (2015-2017)
}

The Classroom in Publications of the História Hoje Journal (2015-2017)

Carmem Zeli de Vargas Gil*

\section{RESUMO}

Este artigo analisa a abordagem da sala de aula nas publicações da Revista História Hoje (RHHJ) no período de 2015 a 2017. Foram identificadas 84 publicações entre os dossiês e as diferentes seções nos quatro volumes estudados. $\mathrm{Na}$ leitura dos materiais se destacaram os temas, a inserção dos/as organizadores/ as dos dossiês e a abordagem da sala de aula nos artigos e nas seções. O texto contempla também um breve exercício de análise com os dados apresentados por Oldimar Cardoso et al. neste mesmo dossiê a respeito das palavras utilizadas nos artigos da RHHJ 2012-2020, reunidas a partir de um algoritmo desenvolvido por ele e por Marco Costa. O estudo dos quatro volumes da RHHJ permitiu vislumbrar a importância da sala de aula nas pesquisas em ensino de História no Brasil, indicando a relevância de se historicizar a prática de sala de aula e não só a História como disciplina. Palavras-chave: Revista História Hoje; ensino de História; sala de aula.

ABSTRACT
This article analyses how the classroom is approached in the História Hoje Journal (RHHJ) publications, over the period from 2015 to 2017. 84 publications were identified among the dossiers and different sections of the four examined volumes. During reading, the subjects, the inserts form dossier organizers and the outlook of the classroom inside articles and sections were highlighted. This article also comprises a brief exercise on analyzing the data presented by Oldimar Cardoso et al. on this same dossier, about the words utilized on articles from RHHJ during 2012 to 2020 , gathered from an algorithm developed by himself and Marco Costa. The study of those four RHHJ volumes allowed us to catch a glimpse on how valuable the classroom is when researching on the teaching of Brazilian History, indicating the significance of historicizing the classroom practice and not merely History as a subject.

Keywords: História Hoje Journal; History teaching; classroom.

* Universidade Federal do Rio Grande do Sul (UFRGS), Porto Alegre, RS, Brasil. carmemz.gil@ gmail.com 


\section{SITUANDO O ESTUDO}

A Revista História Hoje (RHHJ) é parte de um conjunto de periódicos brasileiros que divulgam a produção de conhecimento em ensino de História, constituindo um importante espaço para identificar os debates do campo do ensino de História no Brasil no âmbito da Anpuh. Em sintonia com os objetivos do dossiê, este texto analisa a abordagem da sala de aula em quatro exemplares da RHHJ, publicados no período da editoria de Cristiani Bereta da Silva (2015-2017). Este número especial tem o mérito de produzir conhecimento sobre uma das principais revistas do campo do ensino de História, possibilitando, talvez, indicar pistas sobre os rumos desse campo, visto que a RHHJ publica resultados de pesquisas, relatos de experiências, inovações didáticas e, ao mesmo tempo, é um espaço institucional de debates sobre as lutas, conquistas e desafios do ensino da História na Educação Básica, no Ensino Superior e em diferentes espaços não escolares. Destacam-se como momentos importantes da revista a sua reestruturação em 2011, passando a focalizar as interfaces entre História e ensino de História e a seleção de propostas de dossiês temáticos, por meio de chamadas públicas, a partir de 2013.

Para realizar este estudo foram revisados quatro números da RHHJ, n. 8, n. 9 , n. 10 e n. 11 , correspondentes aos anos de 2015 ( $2^{\circ}$ semestre), 2016 ( $1^{\circ} \mathrm{e}$ $2^{\circ}$ semestres) e 2017 ( $1^{\circ}$ semestre). Nesses números, foram identificadas as seções da Revista, como apresentado na Tabela 1.

Identificadas as 84 contribuições, definiram-se as seguintes orientações para a leitura dos materiais: a) destacar os temas, a filiação institucional dos/ as organizadores/as dos dossiês; b) destacar pesquisas que envolvem observações ou intervenções em sala de aula dos artigos avulsos; c) destacar artigos que tratavam de pesquisas sobre a sala de aula, analisando palavras-chave que dessem pistas dos conceitos/categorias abordadas; d) registrar o que emergia sobre a presença da sala de aula em cada seção, com maior atenção à seção História Hoje na Sala de Aula.

Após esse levantamento de dados, foi proposta uma entrevista ${ }^{1}$ com a editora em torno dos seguintes temas: cenário político do período em questão e os desafios para o ensino da História; a importância de uma revista sobre ensino nesse cenário e as ações da entidade na defesa do ensino da História. 
Tabela 1 - Seções da Revista História Hoje, 2015-2017.

\begin{tabular}{|c|c|c|c|c|c|c|c|}
\hline Revista & $\begin{array}{c}\text { Artigos } \\
\text { Dossiês }\end{array}$ & Entrevista & $\begin{array}{c}\text { Falando } \\
\text { História } \\
\text { Hoje }\end{array}$ & $\begin{array}{c}\text { HH Sala } \\
\text { de Aula }\end{array}$ & $\begin{array}{c}\text { Artigos } \\
\text { Avulsos }\end{array}$ & Resenhas & E-Storia \\
\hline $\begin{array}{c}\text { V. } 4 \text {, n. } 8 \\
\text { Jul-dez 2015 }\end{array}$ & 8 & 1 & 1 & 1 & 3 & 2 & 2 \\
\hline $\begin{array}{c}\text { V. 5, n. 9* } \\
\text { Jan-jun 2016 }\end{array}$ & 7 & 2 & 1 & 1 & 2 & 3 & 1 \\
\hline $\begin{array}{c}\text { V. 5, n. 10 } \\
\text { Jul-dez 2016 }\end{array}$ & 6 & 1 & 1 & 1 & 3 & 2 & 1 \\
\hline $\begin{array}{c}\text { V. 6, n. 11 } \\
\text { Jan-jun 2017 }\end{array}$ & 6 & 1 & 3 & 4 & 3 & 2 & 1 \\
\hline
\end{tabular}

Fonte: Elaboração da autora.

*Seção Temática Especial (espanhol) com 6 artigos.

O foco de análise na sala de aula tem relação com uma forma de se "ler" o campo de pesquisa em ensino de História, buscando evidenciar as conexões e as distinções entre o ensino de História como campo de atuação profissional/ partilha de experiências/formação e o ensino de História como objeto de estudo de pesquisadores não da História ou da Educação, mas de pesquisadores que se dedicam a interrogar o ensino de História com as ferramentas teórico-metodológicas que escolhem de acordo com sua pergunta de pesquisa. Portanto, a escolha da sala de aula como critério para ler as produções da RHHJ, nos volumes de 2015-2017, diz respeito à defesa da escola pública, das professoras da Educação Básica e Superior e de um tipo de pesquisa que se propõe a compreender o que ocorre em um espaço tão complexo e, por vezes, alvo de muitas simplificações como a sala de aula.

Este texto está organizado em três partes que sintetizam o que foi possível compreender com a leitura dos quatro volumes. No primeiro, trata-se das diretrizes da Anpuh para o ensino da História. No segundo, discute-se a presença/ausência da sala de aula nos dossiês e seções da RHHJ. No terceiro tópico, por fim, amplia-se a reflexão com as palavras em destaque nas publicações dos quatro volumes da RHHJ reunidas a partir de um estudo de Oldimar Cardoso. 


\section{DIRETRIZES DA ANPUH PARA O ENSINO DA HISTÓRIA}

As pesquisas em ensino de História cresceram tanto nos últimos anos que dificilmente podemos rastreá-las. No Brasil, ainda podemos dizer que, nos anos 1980 e 1990, as investigações foram pautadas por diferentes ênfases: metodologias, formação de professores, livros didáticos e aprendizagens dos alunos, embora tais temas tenham ganhado contornos diferentes no decorrer dos tempos. Portanto, não se pode dizer que não há novidade, ou seja, o que se discute hoje não é a mesma coisa que se discutia sobre metodologias, formação de professores ou aprendizagens em décadas passadas. Por exemplo, as pesquisas em livros didáticos, que nos anos 1980 e 1990 estavam centradas no conteúdo dos livros, passam a incorporar outras perspectivas como apropriações pelos professores e estudantes, produção do livro, mercado editorial e políticas públicas. Hoje o campo se amplia com temas sobre gênero, tecnologias digitais, relações étnico-raciais, patrimônio, entre outros, mas permanece a necessidade de escrevermos mais sobre a investigação em ensino de História, que não estuda o passado, e sim o presente para compreender o que ocorre quando se utiliza o conhecimento histórico. Os textos de Sonia Miranda (2019); Mauro Coelho e Taissa Bichar (2019); Flávia Caimi e Letícia Mistura (2019; 2020); Itamar Freitas e Margarida Oliveira (2021); Ilka Mesquita (2017); Aryana Costa e Margarida Oliveira (2007) apresentam dados importantes para se construir um panorama do campo do ensino de História hoje. Houve um crescimento considerável do número de grupos, linhas de pesquisa e programas de mestrado profissional em ensino de História que articulam saberes das áreas da Educação e da História, embora nem sempre os pesquisadores tenham relação direta com o ensino de História.

$\mathrm{Na}$ RHHJ, encontramos pistas sobre a atuação da Anpuh em relação ao ensino de História. Os editoriais são um indício da atuação da entidade no debate sobre a Base Nacional Comum Curricular, protestos contra a Reforma do Ensino Médio e manifestações públicas de apoio aos professores da Educação Básica e Superior que sofreram perseguições políticas, além da atuação no projeto de profissionalização do historiador, entre outras ações.

Nos quatro volumes, os editoriais sinalizam o envolvimento da entidade com as questões polêmicas do ensino da História, além de indicar a posição crítica da editora Cristiani Bereta. Nos editoriais, ela registra os ataques à dis- 
ciplina, aos professores/as de História e convoca a pensar as funções sociais do ensino de História. Ou seja, a editora não se limitou a resumir os artigos dos dossiês ou das seções, mas reafirma a RHHJ como espaço de debate político do campo do ensino de História.

No editorial de 2015, ela registra o lançamento da proposta da Base Nacional Comum Curricular (BNCC) e a discussão que se forma a partir da publicação da primeira versão. Cristiani localiza o ensino de História "no centro de um importante debate público que envolve sujeitos situados em diferentes lugares de atuação profissional e com relações distintas de aproximações e distanciamentos com a Educação Básica” (SILVA, 2015, p. 7). Ao mesmo tempo reforça a ideia de que "os embates e as divergências sobre o currículo de História" (ibidem) reafirmam a relevância política e social da História e de seu ensino.

O editorial de 2016-1 inicia assim: "A Revista História Hoje apresenta seu primeiro número de 2016. Ele chega em boa hora, como contribuição e posicionamento político em favor de um ensino de História que seja capaz de dotar de inteligibilidade as experiências sociais[...]" (SILVA, 2016, p. 1). No texto, a editora manifesta o repúdio da Revista aos "projetos impulsionados pelo movimento 'Escola sem Partido"”, que "pretende inibir a pluralidade, o pensamento crítico e o debate irrenunciáveis na proposta de ensino de História que acreditamos e defendemos" (SILVA, 2016, p. 3).

No editorial de 2016-2, ela retoma momentos da história do Ensino Médio, observando a não superação da dualidade entre "preparar para o mundo do trabalho ou para a continuidade dos estudos" (SILVA, 2016b, p. 2). De forma enfática, questiona a aprovação da reforma do Ensino Médio por Medida Provisória (746/2016) e reafirma a posição da Revista História Hoje em acompanhar "o manifesto da Associação Nacional de História - ANPUH que denuncia a forma autoritária do governo ao propor a reforma do Ensino Médio via Medida Provisória" (SILVA, 2016b, p. 2).

No editorial de 2017, Cristiani reforça a posição da revista como fórum de debate em torno das lutas do ensino de História e salienta a relevância de "publicar os números da revista com regularidade, abrindo espaço para diferentes pesquisas com recortes temáticos e abordagens variados relacionados ao ensino de História [como] uma forma de lutar pelo ensino de História nas escolas, em diferentes níveis” (SILVA, 2017, p. 1). Ainda questiona: “[...] a 
quem interessa a exclusão da disciplina História na relação de componentes curriculares obrigatórios para o Ensino Médio?” (ibidem).

Os editoriais de Cristiani Bereta da Silva ${ }^{2}$ constituem um mapa das grandes questões que envolvem o campo do ensino de História nos anos de 2015, 2016 e 2017: a discussão sobre a Reforma do Ensino Médio, disputas em torno do papel do Estado para a manutenção das conquistas educacionais, da cidadania e da justiça social; Base Nacional Comum Curricular; o enfrentamento aos projetos reacionários; o combate ao preconceito e a desigualdade social e as lutas dos agentes do campo para reafirmá-lo como espaço de resistência e fortalecimento da ação política, pública e coletiva. Os editoriais anunciam a RHHJ como um espaço de resistência para o ensino da História.

$\mathrm{Na}$ entrevista, Cristiani destaca que seu maior desafio não foram os editoriais, e sim os bastidores da Revista, buscando estabelecer um fluxo editorial eletrônico por meio do Open Journal System (OJS); atualização do OJS e do layout da RHHJ; obtenção do Digital Object Identifier (DOI) e ajuste de periodicidade para atender as exigências de indexadores internacionais.

A partir de novembro de 2015, com o apoio da diretoria da Anpuh, a revista passou a ser hospedada na Lepidus Tecnologia: Periódicos em Nuvens que também atualizou o sistema [...] criando novo layout para a revista, mais leve e atrativo para publicações em formato digital.

Com o objetivo de buscar indexadores mais bem valorizados na área e assim poder concorrer em editais de financiamento do CNPq e CAPES, a revista passou a atribuir Digital Object Identifier (DOI) a todos os artigos a partir de agosto de 2015. A atribuição do DOI é uma das exigências dos melhores indexadores. Com o fluxo organizado me preocupei com a indexação da revista em bases internacionais. Descobri ao solicitar a indexação à REDALYC que a revista precisava ajustar a periodicidade [...]. Quando entreguei a editoria da RHHJ a Paulo Eduardo Dias de Mello (UEPG) estava com o número do segundo semestre julho/dez de 2017 pronto para publicação em julho e a partir de então ele poderia voltar a solicitar indexação à REDALYC e a DOAJ, porque todas as outras exigências já haviam sido cumpridas. (Cristiani Bereta da Silva, em entrevista, março de 2021)

Internamente, é um momento de reconfiguração da Revista, passando a ser semestral e em formato eletrônico. Silva lembra que, em 2011, a Revista modi- 
ficou a sua linha editorial nos períodos de Patrícia Melo Sampaio (UFAM) e de Mauro Cezar Coelho (UFPA). Era necessário continuar qualificando a RHHJ.

Outro indício da aproximação da Anpuh com o ensino de História está no artigo 5 do Estatuto da Associação Nacional de História: “A ANPUH tem por objeto a proteção, o aperfeiçoamento, o fomento, o estímulo e o desenvolvimento do ensino de História em seus diversos níveis, da pesquisa histórica e das demais atividades relacionadas ao ofício do historiador". O artigo 13 do Regimento Interno da Anpuh prescreve que a Revista História Hoje deverá "incluir artigos voltados preferencialmente à questão do ensino de História em seus diversos níveis e aos debates atuais relativos ao conhecimento histórico." Pode-se dizer, então, que a própria RHHJ é uma política da entidade voltada ao campo, principalmente após 2011, quando sua linha editorial é redefinida para o ensino da História.

Os editais da RHHJ para inscrição de dossiês recomendam a proposição dos mesmos por até dois professores, preferencialmente um vinculado a um programa de pós-graduação credenciado na CAPES e o outro vinculado a uma instituição de ensino de Educação Básica, Profissional e Tecnológica e/ou Superior. Tal recomendação é indício de que a entidade se movimenta no sentido de ampliar a aproximação com professores da Educação Básica. Um dos critérios para a proposição dos dossiês é a justificativa da relevância dos temas/ problemas para o ensino de História, o que indica a intenção de fortalecê-lo como um campo de pesquisa. $\mathrm{Na}$ entrevista, Cristiani afirmou:

A Anpuh tem avançado bastante no decorrer de sua história em relação ao ensino e à formação docente, é inegável o aumento de sensibilidade para esses temas e questões que lhe são decorrentes nos últimos anos. A própria mudança do escopo da História Hoje, em 2011, e o apoio financeiro concedido a ela são indícios disso. Vejo como positivo também o espaço que o GT de Ensino de História e Educação conquistou na própria diretoria com voz, por exemplo, na articulação da $2^{\circ}$ Secretaria. Contudo, entendo que ainda há muito o que se fazer para que possamos de fato visualizar "diretrizes da Anpuh para o ensino de História", articuladas as suas ações políticas mais abrangentes. (Cristiani Bereta da Silva, em entrevista, março de 2021)

Ela destaca ainda a necessidade de consolidar a formação do profissional em História, no Brasil, associada à pesquisa no exercício da docência na Educação Básica. A grande maioria dos professores que concluem mestrado e dou- 
torado seguirão atuando na Educação Básica. Portanto, as "políticas públicas educacionais, formação docente, ensino e aprendizagem na Educação Básica etc. devem ser estruturais nos debates da Anpuh e ganhar escopo em suas diretrizes" (Cristiani Bereta da Silva, em entrevista, março de 2021).

Outro aspecto a destacar em relação às diretrizes da Anpuh para o ensino diz respeito ao diálogo com pesquisadores do ensino de História de outros países. A edição n. 9, de 2016, trouxe a Seção Temática Especial com seis artigos sobre o ensino e a aprendizagem das Ciências Sociais e da História, de autoria de professores/as argentinos. Entre as quatro entrevistas apresentadas nos volumes em análise, duas são com pesquisadores estrangeiros. Nos artigos que compõem os dossiês tem-se pesquisadores/as de Portugal, Uruguai e Argentina, evidenciando a intenção em ampliar o diálogo com a produção de outros países, o que permite pensar o campo do ensino em relação às produções de pesquisadores/as da América Latina e Europa.

\section{A SALA DE AULA NOS DOSSIÊS E SEÇÕES DA RHHJ}

O tema da sala de aula se reveste de importância na análise da RHHJ, sobretudo porque a sala de aula é um dos espaços privilegiados para as pesquisas em ensino de História. A Tabela 2 apresenta os quatro volumes analisados, com seus respectivos temas e organizadores/as.

Tabela 2 - Temas e autores/as dos dossiês.

\begin{tabular}{|c|l|l|}
\hline Revista & \multicolumn{1}{|c|}{ Tema } & \multicolumn{1}{|c|}{ Organizadores/as } \\
\hline $\begin{array}{c}\text { N. } 8 \\
2015\end{array}$ & $\begin{array}{l}\text { Ensino de História e linguagem: } \\
\text { discurso, narrativa e práticas de } \\
\text { significação do tempo }\end{array}$ & $\begin{array}{l}\text { Maria Aparecida Lima dos Santos } \\
\text { Patrícia Bastos de Azevedo }\end{array}$ \\
\hline N. 9 & $\begin{array}{l}\text { Ensino de História e consciência } \\
\text { histórica }\end{array}$ & $\begin{array}{l}\text { Luis Alberto Marques Alves } \\
\text { Marcelo de Mello Rangel } \\
\text { Tatyana Amaral Maia }\end{array}$ \\
\hline $\begin{array}{l}\text { N. } 10 \\
2016\end{array}$ & $\begin{array}{l}\text { Ensino de História na educação } \\
\text { profissional }\end{array}$ & $\begin{array}{l}\text { Olivia Morais Medeiros Neta } \\
\text { Francisco das Chagas Silva Souza }\end{array}$ \\
\hline $\begin{array}{l}\text { N. } 11 \\
2017\end{array}$ & Música e ensino de História & $\begin{array}{l}\text { Olavo Pereira Soares } \\
\text { Miriam Hermeto }\end{array}$ \\
\hline
\end{tabular}

Fonte: Elaboração da autora. 
Observando os currículos dos/as organizadores/as dos dossiês na Plataforma Lattes, identificam-se registros da expressão "ensino de História” no título de projetos de pesquisa, no título de projetos de extensão, em área de atuação, subárea de atuação, na linha de pesquisa. Dois currículos não possuem qualquer vinculação. Cabe destacar que os currículos de todos evidenciam inserção nos temas dos dossiês e as universidades dos proponentes dos dossiês são: UFMS, UFRRJ, U. Porto, UFOP, PUC-RS, UFRN, UFSC, UNIFAL-MG, UFMG.

As temáticas dos dossiês têm relação com questões teórico-metodológicas do campo do ensino de História, educação profissional e a música como possibilidade de aproximação entre o ensino e a pesquisa. Nas apresentações dos dossiês encontramos pistas para identificar movimentos do campo do ensino da História. No dossiê "Ensino de História e linguagem: discurso, narrativa e práticas de significação do tempo", a centralidade é a sala de aula. Autores discutem observações, narrativas de professores, manuscrito escolar; narrativas históricas produzidas por crianças e jovens, entre outras situações; propõem o diálogo com a Literatura e, no fechamento do dossiê, o artigo da pesquisadora uruguaia Ana Zavala, "Pensar 'teóricamente' la práctica de la enseñanza de la Historia” provoca-nos a pensar o/a professor/a como teórico de sua própria prática. Já o dossiê "Ensino de História e consciência histórica" evidencia as possibilidades das proposições teóricas de Jörn Rüsen para o campo do ensino de História. Nos artigos, o conceito de consciência histórica é apropriado pelos pesquisadores para refletir sobre a aprendizagem da História dentro e fora da sala de aula. O primeiro artigo, do professor Luís Alberto Marques Alves (Universidade do Porto), evidencia a aproximação entre professores brasileiros e portugueses no que se refere ao estudo da obra do pesquisador alemão. O dossiê "Ensino de História na educação profissional" indica a aproximação entre o campo do ensino de História e o debate sobre currículo integrado ou a articulação entre a educação profissional técnica e a formação geral, visibilizando práticas pedagógicas dos professores no Ensino Médio integrado à Educação Profissional, interdisciplinaridade e concepção de trabalho para os professores de História. No artigo "Ensinar História no ensino médio integrado à Educação Técnica Profissional: muitas questões, grandes desafios”, as autoras analisam os desafios que envolvem "o trabalho dos docentes que ensinam a disciplina nessa modalidade, nos Institutos Federais" (ALEM e PEREIRA, 2016, p. 47). O dossiê "Música e ensino de História" indica o movi- 
mento de aproximação do campo do ensino de História com o campo da pesquisa em educação, visto que a música é abordada "como objeto de estudo e como fonte para a construção de capacidades voltadas à aprendizagem e à construção do conhecimento histórico pelos estudantes" (HERMETO e SOARES, 2017, p. 4). Os artigos apresentam estudos sobre a relação entre a música e o campo do ensino de História, na medida em que buscam compreender os usos da música na aprendizagem dos contextos históricos.

Quanto ao conjunto de 27 artigos apresentados nos quatro dossiês, as temáticas tratadas estão, obviamente, relacionadas à proposta de cada dossiê. No que diz respeito à abordagem da sala de aula, dividiu-se os artigos em dois grupos: 1. pesquisas sobre a sala de aula; 2 . pesquisas que envolvem observações ou intervenções em sala de aula. No primeiro grupo ficaram os artigos que tratavam da sala de aula desde fora, envolvendo, entre outros objetos, políticas educacionais, contribuições filosóficas e teórico-metodológicas e documentos curriculares. No grupo dois ficaram os artigos que tratam da sala de aula, a partir de um olhar "de dentro", focalizando o que ocorre nos processos de ensinar e aprender História. Apenas um artigo não pôde ser classificado em nenhum desses grupos.

Tabela 3 - A sala de aula nos artigos dos quatro dossiês.

\begin{tabular}{|l|c|c|c|c|}
\hline \multicolumn{1}{|c|}{ Revista } & Qtd artigos & $\begin{array}{c}\text { Observação/ } \\
\text { intervenção em } \\
\text { sala de aula }\end{array}$ & $\begin{array}{c}\text { Pesquisas sobre } \\
\text { a sala de aula }\end{array}$ & Outro \\
\hline Revista n. 8 & 8 & 5 & 3 & \\
\hline Revista n. 9 & 7 & 5 & 2 & 1 \\
\hline Revista n. 10 & 6 & 4 & 2 & 01 \\
\hline Revista n. 11 & 6 & 3 & 09 & \\
\hline Totais & 27 & 17 & & \\
\hline
\end{tabular}

Fonte: Elaboração da autora.

Compreende-se que o olhar reflexivo para a sala de aula pode ser proposto a partir de duas abordagens. A primeira foca nas pesquisas na sala de aula (observação ou intervenção) realizadas por um pesquisador externo em cola- 
boração com o/a professor/a, tal como o estudo que analisa as narrativas "de professores, em sala de aula, para a construção do saber histórico escolar e também para a produção de identidades docentes" (MONTEIRO e AMORIM, 2015, p. 16). A segunda privilegia as "ideias de professores e alunos acerca de como a História, que se expressa narrativamente, forma e contribui para a tomada de decisão numa lógica de orientação temporal do eu e do nós, espelho da sua consciência histórica" (GAGO, 2016, p. 81).

No grupo de pesquisas sobre a sala de aula realizadas por pesquisador/a externo/a, tem-se, por exemplo, o estudo que "parte das categorias centrais da Didática da História Alemã e investiga as contribuições que a chamada Estética Filosófica Moderna pode fornecer para a percepção de um momento específico da consciência histórica e do aprendizado histórico" (SADDI, 2016, p. 114). Tem-se também o estudo que privilegiou a "interface temporalidade-identidade tal como hegemonizada nos textos curriculares normativos, mais particularmente nos Parâmetros Nacionais Curriculares de História produzidos nos anos de 1990" (GABRIEL, 2015, p. 34). Se a investigação em ensino de História é aquela que formula perguntas, indica abordagens e enfoques relacionados aos processos de ensinar e aprender História, a sala de aula é um dos espaços privilegiados dessas pesquisas.

Esses dois critérios elencados para o agrupamento dos artigos dimensionam a importância da sala de aula nas pesquisas do campo do ensino de História na RHHJ, que, por sua vez, não está desvinculada de discussões e investigações nacionais e mesmo internacionais. A sala de aula é a preocupação dos/ as autores/as dos artigos deste periódico, seja para pensar o ensino de História, a formação do/a professor/a ou a produção de materiais didáticos. Pesquisas na sala de aula, sobre a sala de aula, produzidas pelos próprios professores e professoras ou por pesquisador/a externo/a indicam que esse espaço é o privilegiado nas interrogações de quem quer saber mais sobre o ensino da História, embora saibamos que há muitos outros, como museus, arquivos, meios de comunicação impresso e virtual, entre outros.

A leitura dos artigos que compõem os quatro dossiês permite destacar um conjunto de palavras-chave que emerge como preocupação central dos pesquisadores e pesquisadoras que se voltam para a sala de aula: narrativa, identidade docente, temporalidades, significações do tempo, letramento, espaço, consciência histórica, educação patrimonial, currículo integrado, trabalho docente, his- 
tória afro-brasileira, música. Trata-se de temas clássicos das pesquisas em ensino de História, assim como temas emergentes que ampliam categorias, metodologias e referenciais teóricos que marcam as investigações desse campo.

Em relação às seções, o site da RHHJ informa que, em 2011, o Conselho Editorial criou as seções História Hoje na Sala de Aula, E-Storia e Falando de História Hoje. Artigos avulsos e resenhas também passam a compor a revista. A leitura das seções (nos quatro volumes) permitiu organizar as temáticas em três categorias: continuidades (temas clássicos ${ }^{3}$ nas produções do campo do ensino), emergências (novos temas que passam a compor as preocupações dos/ as pesquisadores/as) e contingências (temas relacionados a projetos criados no âmbito de políticas públicas).

Tabela 4 - A sala de aula nas seções dos quatro volumes da RHHJ.

\begin{tabular}{|c|c|c|c|}
\hline $\begin{array}{l}\text { As seções nos } \\
\text { quatro dossiês }\end{array}$ & Continuidades & Emergências & Contingências \\
\hline $\begin{array}{l}\text { Falando de } \\
\text { História Hoje }\end{array}$ & $\begin{array}{l}\text { Metodologias de } \\
\text { trabalhos em sala de aula }\end{array}$ & $\begin{array}{l}\text { Educação popular } \\
\text { Abordagem de } \\
\text { gênero }\end{array}$ & $\begin{array}{l}\text { Extensão } \\
\text { universitária }\end{array}$ \\
\hline $\begin{array}{l}\text { História Hoje na } \\
\text { Sala de Aula }\end{array}$ & $\begin{array}{l}\text { Formação de professores } \\
\text { Livros didáticos } \\
\text { Metodologias para aulas } \\
\text { Temporalidades }\end{array}$ & Aula invertida & - \\
\hline Resenhas & $\begin{array}{l}\text { Currículo } \\
\text { Cinema } \\
\text { Conhecimento histórico } \\
\text { Livro didático } \\
\text { Cidadania }\end{array}$ & Usos do passado & $\begin{array}{l}\text { Ensino Médio } \\
\text { Integrado }\end{array}$ \\
\hline Artigos avulsos & $\begin{array}{l}\text { Currículo } \\
\text { Livro didático } \\
\text { Metodologias para aulas } \\
\text { Formação de professores }\end{array}$ & $\begin{array}{l}\text { Redes educativas } \\
\text { construídas em um } \\
\text { Terreiro de } \\
\text { Candomblé } \\
\text { Abordagem de } \\
\text { Gênero } \\
\text { África e cultura } \\
\text { afro-brasileira }\end{array}$ & PIBID \\
\hline
\end{tabular}

Fonte: Elaboração da autora. 
A seção E-Storia, dada a sua especificidade em tratar das Tecnologias Digitais da Informação e Comunicação (TDIC), não cabe na classificação acima, destacando-se pelas permanentes transformações em suas abordagens. Da informática na educação, passando pelas "novas” tecnologias, novas linguagens, TICs e cultura digital ao debate mais recente sobre história digital e história pública no ensino. Nos quatro dossiês identificou-se artigos que abordam as tecnologias digitais como recurso didático capaz de entusiasmar os estudantes para a aprendizagem participativa; o uso escolar da internet e a inserção das redes sociais no fazer docente com ênfase no Facebook e nos aplicativos móveis no ensino de História.

Parece que a pergunta como ensinar história continua mobilizando os pesquisadores/as que publicaram seus artigos nesses volumes da RHHJ. Além do livro didático, as metodologias de ensino continuam a justificar as pesquisas. No V Encontro Nacional Pesquisadores do Ensino de História, ocorrido em João Pessoa, em 2001, Ernesta Zamboni havia escrito uma síntese sobre as tendências dos estudos do campo do ensino que vale lembrar aqui. Segundo ela, na década de 1970, os trabalhos eram dominantemente relatos de experiência; nos anos 1980, a dimensão política e ideológica da prática pedagógica dava o tom para a produção dos estudos e foram frequentes trabalhos sobre diferentes linguagens, principalmente, sobre a história em quadrinhos, cinema e música. Nos anos 1990, as ditas "novas linguagens" ganham centralidade e pode-se dizer que, em 2021, ensinar História em meio à cultura digital vem ganhando centralidade nos estudos do campo (ZAMBONI, 2000/2001).

As metodologias continuam a interrogar os pesquisadores. Primeiro, é parte do ofício perguntar-se sobre como ensinar; segundo, as respostas a essa pergunta se modificam em cada período. Mas isso faz do campo do ensino um "lugar da prática", vazio de teorias e de saberes? No dia a dia são comuns as frases: "teoria se aplica na prática" e a "prática se nutre da teoria", o que faz emergir uma superioridade da teoria e cria as divisões - o/a pesquisador/a e o/a professor/a; os teóricos e os práticos. Seria o caso, por outro lado, de se pensar o campo do ensino como o "lugar político" no qual os saberes são selecionados, afirmados, negados, contestados? (MONTEIRO e RALEJO, 2019, p. 7). Talvez fosse importante ampliar a mirada e romper com o paradigma construído em torno da polarização teoria/prática que alimenta hierarquizações entre campos de pesquisa, disciplinas e áreas de conhecimento.

Sobre essas interrogações, os estudos da pesquisadora uruguaia Ana Za- 
vala constituem uma inspiração, pois, segundo ela, os problemas do ensino de História não se resolvem mediante a conversão de teorias em prescrições práticas, sendo importante mudar a compreensão que se tem da relação teoria e prática. Zavala (2008, p. 190) questiona os modelos de pesquisa em educação que invisibilizam os professores enquanto teóricos de suas práticas e propõe a investigación práctica de la práctica de la enseñanza em que "o trabalho de teorização é assim incorporado e entrelaçado com a dimensão prática do ensino de história" (tradução nossa). Não cabe nos limites deste texto seguir essa discussão, mas Zavala convida os pesquisadores a aproximar o que, geralmente, aparece separado.

Outro ponto a destacar na tabela acima diz respeito à ausência de estudos que tratem da história dos povos indígenas. Nos quatro volumes da RHHJ (2015-2017), não há qualquer artigo, entrevista, resenha, artigo avulso ou dossiê que trate dessa questão. No conjunto dos volumes da RHHJ de 2012-2020, encontramos um dossiê sobre o assunto: Ensino de História e História Indígena (v. 1, n. 2, 2012). De qualquer forma, são dois anos sem qualquer publicação sobre os povos indígenas no principal periódico do campo do ensino de História no Brasil. Esse silêncio incomoda muito quando se tem a oportunidade de ler os trabalhos de Giovani José da Silva, Cida Bergamaski e Luma Prado ou de Ailton Krenak. Em 2020, Raoni, Sônia Guajajara, Célia Xacriabá, Maria Martins Santos (Tremenbé) e outras lideranças, representantes de 45 povos indígenas, assinaram o Manifesto do Piaraçu. No documento, eles reivindicam ensino médio e universitário para os jovens indígenas, denunciam o sucateamento da universidade pública, repudiam a perseguição e criminalização das lideranças indígenas e exigem que o Estado brasileiro cumpra a constituição e se "responsabilize pelo envenenamento do ar, do solo e dos rios causado pelo uso irresponsável e descontrolado de agrotóxicos no entorno de nossas terras". Afirmam ainda que "essa luta não é apenas dos povos indígenas, mas de todos nós, é uma luta pela vida do planeta” (MANIFESTO, p. 4). Exatamente por isso, o campo do ensino de História necessita de mais pesquisas e projetos para reconhecer a importância dos povos indígenas na gestão dos biomas terrestres, na defesa da agrobiodiversidade e no fortalecimento de suas lutas. Ao mesmo tempo, a inexpressividade de trabalhos em relação à história e cultura africana e afro-brasileiras obriga os pesquisadores a se interrogarem: até quando o ensino de história indígena e o ensino de história e cultura africanas e afro-brasileiras serão tratados como temas emergentes no campo? 
Considerando que o foco da análise aqui é a sala de aula, observa-se que os sete textos publicados na seção História Hoje na Sala de Aula apresentam experiências de professores do ensino superior e da educação básica sobre suas aulas ou disciplinas e, ao fazerem esse movimento, apresentam materiais utilizados, propostas de aulas, teorias e metodologias perseguidas. No artigo "Uma experiência de formação de professores em torno do conhecimento histórico-educacional na Universidade Federal de Uberlândia”, Décio Gatti refletiu sobre suas experiências de ensino na disciplina História da Educação e apresenta os processos de escolarização no Brasil, em Minas Gerais e no Triângulo Mineiro, a partir de um conjunto muito rico de materiais utilizados em suas aulas (GATTI, 2015).

Em "Produção de livros didáticos no mestrado profissional de História: relato de experiência a partir de uma disciplina da UFRB”, Leandro Almeida discute os saberes implicados na produção de livros paradidáticos em formato digital, realizados pelos mestrandos na disciplina. Por tratar-se de professores/ as que cursam o Mestrado Profissional, é surpreendente a conclusão do autor de que mestrandos tiveram dificuldades com a construção de uma "linguagem voltada aos alunos da educação básica” (ALMEIDA, 2016). Por outro lado, é compreensível a dificuldade dos mestrandos com "os saberes de edição e diagramação dos livros", embora esse seja um exemplo do grande desafio que se tem hoje, tanto na escola quanto na universidade: criar materiais didáticos de forma interdisciplinar. No contexto da cultura digital, a produção de conhecimento necessita de profissionais de diferentes áreas (Ciências da Computação, Educação, História, Engenharia, Design etc.) e esse fenômeno traz, portanto, a possibilidade da escola e da universidade serem interdisciplinares.

Em "As três durações de Fernand Braudel no Ensino de História: proposta de atividade", Ricardo Mello analisa uma atividade com alunos da Graduação e do Mestrado em História, sobre a presença múltipla das durações (curta, média e longa) no dia a dia, ou "como o tempo se manifesta na cidade das mais diferentes formas". O autor abre sua sala de aula, mostra fotos da experiência e conclui: "esta é uma atividade que tem mais benefícios que o contrário. Ela, de fato, desperta o interesse dos alunos, estimula o raciocínio e abre novas oportunidades de entendimento da realidade [...]" (MELLO, 2017, p. 252).

No artigo "Ditadura militar sob o olhar de composições musicais", Flavia Silva analisa o uso de letras de canções populares das décadas de 1960 e 1970 com alunos do último ano do Ensino Fundamental para abordar a Ditadura 
Militar no Brasil. Apresenta os momentos do desenvolvimento do projeto e destaca a capacidade crítica dos estudantes na análise das letras. Nas conclusões, ela indica que "foi possível verificar o alcance e o encanto que essa ferramenta, empregada como objeto e fonte de estudo, exerceu sobre os educandos, circunstância que lhes possibilitou interagirem melhor com o tema proposto" (SILVA, 2017, p. 269).

No artigo "Flipped classroom em História e Geografia de Portugal: contributos de um estudo numa turma do $5^{\circ}$ ano", Cláudia Rolo e Pedro Teixeira Pereira questionam se os alunos do $5^{\circ}$ ano de uma escola pública da zona rural de Portugal estão preparados para responder às exigências do século XXI e como o ensino da História e Geografia de Portugal pode contribuir. Para isso, o autor e a autora propuseram a inversão da prática docente com uso da flipped classroom. Na análise dos resultados, eles indicam: “A implementação da flipped classroom é exequível no processo de ensino e aprendizagem da História e Geografia [...] e os alunos tornaram-se mais responsáveis e conscientes do seu próprio processo de aprendizagem". Além disso, concluem que “o tempo despendido na planificação, gravação e edição das videoaulas foi largamente compensado pela reação dos alunos que se tornaram mais empenhados na sua aprendizagem" (ROLO e PEREIRA, 2017, p. 292).

No artigo "Na trilha sonora da História: a canção brasileira como recurso didático-pedagógico na sala de aula”, Luís Guilherme Duque discute a canção brasileira como recurso didático nas aulas de História do Brasil do curso de História da Faculdade Cenecista de Osório-RS (FACOS), indicando que essa proposta surgiu de "demandas apontadas pelos alunos de graduação, baseadas em alguns questionamentos básicos, a exemplo de 'como, quando e por que utilizar canções como recurso didático-pedagógico em sala de aula?’” (DUQUE, 2017, p. 296).

No artigo "Guerra do Contestado e ensino de História: sobre os ataques de sertanejos no município de Canoinhas (1914-1916)”, Eloy Tonon e Soeli Lima realizam pesquisa bibliográfica e documental, assim como entrevistas com "professores de História do Ensino Fundamental (séries finais) e do Ensino Médio que atuaram, no ano de 2015, em 22 escolas pertencentes à 26a Gered de Canoinhas (SC)", buscando compreender como a história regional é abordada na educação básica. Após a pesquisa, indica-se que há "uma riqueza de fontes documentais sobre a Guerra do Contestado”. Autores também constaram "pouco conhecimento por parte dos docentes", indicando "a neces- 
sidade de capacitação docente referente ao tema da Guerra do Contestado" (TONON e LIMA, 2016, p. 196).

Nessa seção tem-se, portanto, seis artigos em que os autores/as propõem/ experienciam/analisam suas aulas e em apenas um artigo a sala de aula é estudada por um pesquisador externo. As reflexões empreendidas nas conclusões dos artigos são interessantes para se pensar a tendência de alguns estudos em que a sala de aula, observada de fora, é o lugar da falta; os/as professores/as seriam aqueles para os quais se destinam as prescrições e recomendações. Ana Zavala, em um desafiante artigo intitulado "Historia de un gesto inacabado Lecturas a contrapelo en torno a la emancipación de los docentes”, convida a compreender a pesquisa sobre a prática docente de outra maneira, além daquela que percebe os/as professores/as como incompletos e malsucedidos em suas tentativas de aplicar as ideias pedagógicas dos "pensadores da educação". Nesse texto, a autora revisa um conjunto de autores, ${ }^{4}$ cuja pesquisa "construiu não a emancipação, mas a subalternidade dos professores (sem voz, violência epistêmica, alteridade)" (ZAVALA, 2016, p. 108).

\section{QUATRO VOLUMES DA RHHJ E UM ALGORITMO}

Até aqui, fez-se uma interpretação dos quatro volumes da RHHJ com foco na sala de aula como preocupação dos textos publicados. Outra forma de analisar esse corpus empírico é a partir do modelo de organização dos dados proposto por Oldimar Cardoso, que ele designa como "Ciência Aberta". Em parceria com Marco Costa, Cardoso opera o "método de cotejamento diacrônico de fontes escritas por redes semântico-temporais e de um algoritmo" (CARDOSO et al., 2021, p. 138). ${ }^{5}$

Ao fazer a "comparação digital do corpus completo da Revista História Hoje (2012-2020)" (p. 138), Oldimar Cardoso et al. apresenta as palavras mais utilizadas nos artigos da RHHJ (2012-2020) e convida os pesquisadores a estabelecerem alguma síntese. Portanto, ao rodar esse corpus no algoritmo em desenvolvimento, tem-se as palavras mais citadas nos artigos por ano. Em uma análise semântica, percebe-se que, entre os anos de 2012 a 2020, ${ }^{6}$ a relação entre as palavras "história", "histórico", "ensino" e "professor" é uma constante, embora não se tenha como saber, nesse momento, o sentido em que a palavra foi mais mobilizada (ciência, vida, tempo passado...). Em estabilidade, ${ }^{7}$ aparecem as palavras "história", "ensino" e "poder". Considerando que as duas primeiras pa- 
lavras - "história" e "histórico" - são óbvias por se tratar de um corpus situado no campo do ensino da História, restam as palavras "ensino" e "professor" ou "ensino", "professor" e "poder" como palavras que permanecem muito citadas em todos os volumes de cada ano. A combinação desses étimos sugere que há uma permanência de elementos estruturantes na produção de conhecimento em ensino de História? Se fosse possível afirmar que sim, então, essa resposta conduziria a outra pergunta: as produções do campo do ensino de História que se projetam na RHHJ têm acento em um dos sujeitos do fazer pedagógico - o/a professor/a? A sala de aula na perspectiva de quem aprende estaria mais invisibilizada? Analisando teses e dissertações defendidas entre os anos de 1993 a 2010, Selva Guimarães e Marcos Silva tinham anunciado que os sujeitos investigados no conjunto de trabalhos mapeados era o professor. Segundo ele, "embora as pesquisas reconheçam o papel do aluno como sujeito da aprendizagem [...], os professores em suas várias dimensões são objeto de um número significativo de teses e dissertações" (GUIMARÃES e SILVA, 2014, p. 83, tradução nossa).

Empregando a reunião de palavras conectadas à sala de aula, previamente solicitada a Cardoso, tem-se uma visão geral da rede semântica estabelecida entre 2012 e 2020, como apresentado na Tabela 5.

Tabela 5 - As palavras conectadas a sala de aula no corpus completo da RHHJ.

\begin{tabular}{|c|c|c|c|c|c|c|c|c|}
\hline 2012 & 2013 & 2014 & 2015 & 2016 & 2017 & 2018 & 2019 & 2020 \\
\hline história,19 & professor,39 & professor,22 & história,47 & história,60 & história,69 & história,29 & história,52 & história,47 \\
\hline professor,15 & história,33 & história,19 & professor, 40 & professor,48 & histórico, 50 & professor,24 & ensino,32 & histórico, 43 \\
\hline ensino,12 & ensino,21 & ensino, 18 & ensino,24 & ensino,36 & aluno,41 & aluno,18 & professor, 30 & professor, 35 \\
\hline poder,12 & aluno,20 & histórico,17 & histórico, 23 & aluno, 30 & professor,38 & poder,15 & público,24 & ensino,31 \\
\hline tempo, 10 & escola,19 & aluno,12 & aluno,23 & histórico, 30 & poder,34 & docente, 15 & aluno,24 & aprendizagem ${ }_{1}^{2}$ \\
\hline indigena, 9 & histórico,18 & poder,11 & ensinar, 19 & poder, 28 & ensino,33 & didático, 15 & histórico,24 & aluno, 23 \\
\hline aluno,9 & escolar,15 & trabalho,11 & escolar,17 & whatsapp, 24 & fonte, 33 & ensino,15 & poder,20 & espaç̧o,20 \\
\hline espaço,8 & poder,14 & documento,10 & poder,15 & aprendizagem,2 & atividade, 30 & espaço,13 & escola,19 & poder,20 \\
\hline histórico, 8 & cotidiano, 12 & didático, 9 & pesquisa,15 & pedagógico, 23 & imagem, 24 & escola,12 & educação, 16 & trabalho, 16 \\
\hline cultura,7 & aprendizagem,1 & experiência, 9 & espaço,13 & didático, 21 & documento,24 & aula,11 & espaço,15 & escolar,15 \\
\hline brasileiro, 6 & livro,11 & fonte, 9 & escola,13 & docente, 17 & trabalho, 24 & pedagógico,11 & experiência,14 & pesquisa,14 \\
\hline segundo, 5 & tempo,10 & curso, 9 & social,12 & trabalho,17 & didático, 22 & conteúdo,11 & escolar,13 & didático,14 \\
\hline negro, 5 & público,9 & espaço, 8 & atividade,12 & conteúdo,16 & música,21 & social,10 & conteúdo,12 & estudante,13 \\
\hline memória, 5 & atividade, 9 & arquivo,7 & educação,11 & pesquisa, 16 & brasileiro, 19 & tecnologia,10 & pesquisa, 12 & narrativa, 12 \\
\hline trabalho, 5 & didático,9 & aprendizagem, 6 & didático,11 & contexto,15 & recurso,18 & livro,10 & trabalho,11 & conteúdo,12 \\
\hline
\end{tabular}

Fonte: Elaborada por Oldimar Cardoso et al. 
Interessante observar que quando o algoritmo reúne as palavras que mais se conectaram com a expressão "sala de aula/salas de aula", "professor" assume o primeiro lugar como a palavra mais citada em 2013 e 2014, ficando em segundo lugar em 2012, 2015, 2016 e 2018. A palavra “ensino" fica em terceiro lugar de 2012 até 2016, passa para segundo em 2019 e quarto lugar em 2020. "Aluno" oscila entre quarto, quinto e sexto lugar e a palavra "aprendizagem" oscila entre décimo e oitavo lugares para chegar em terceiro em 2020. Na rede elaborada por Cardoso, aprendizagem tem uma ascensão repentina parecendo, portanto, que nesse corpus empírico, a sala de aula é investigada muito a partir do ensinar e pouco sobre o aprender. Nessa rede semântica, aparece em estabilidade "história", "professor", “ensino", "aluno" e "poder”. Novamente o "aprender" é o étimo menos frequente.

Observando-se somente as palavras que se repetem nos volumes dos semestres de 2015-2, 2016 e 2017-1, outro conjunto de palavras é detectado. Nessa nova disposição, a palavra "história" permanece em primeiro lugar, embora tal fato não seja relevante dada a especificidade do corpus. A palavra "ensino", de terceiro lugar, passa para segundo, em 2017. A palavra "professor" aparece em quarto lugar, nos dois primeiros anos, e cai para oitavo lugar, em 2017. A palavra "aluno" está em $11^{\circ}$ lugar em 2015-2, sexto lugar em 2016 e chega em terceiro lugar em 2017. Os étimos "aprender" e "aprendizagem”, por fim, não aparecem no recorte das 300 palavras mais citadas.

Essas palavras, em evidência nos quatro volumes, podem indicar algumas pistas para facilitar a pesquisa posterior de um elemento no conjunto de produções da Revista. O certo é que encontramos um padrão de palavras que se repetem nas publicações dos quatro volumes da $\mathrm{RHHJ}$ e permanecem bem classificadas no conjunto dos volumes rodados de 2012 a 2020.

Se cruzarmos esse conjunto de palavras que se repetem e os temas das seções dos quatro volumes da RHHJ, podemos evidenciar a continuidade dos temas que, ao longo dos anos 1990, se consolidaram como preocupações do campo do ensino de História: formação do professor de História, livros didáticos, currículo e método de ensino. Em outras palavras, o "como ensinar história" parece ser a preocupação dos pesquisadores e pesquisadoras situados nesse campo. Mas há emergências expressas nas palavras que têm aparecimento repentino. Duas delas são: "gênero", entre as 300 palavras mais citadas no tratamento dos dados dos 
volumes de 2012 a 2020, e a combinação "gênero" e "aula invertida", situadas como emergentes nas seções dos quatro volumes analisados.

\section{PARA CONTINUAR PENSANDO A SALA DE AULA}

Nos quatro volumes da RHHJ, pode-se inferir que o campo se projeta na revista, buscando compreender a sala de aula. Ela é a preocupação dos pesquisadores que publicaram seus artigos nos quatro volumes. Observações de aulas, intervenções junto aos professores/as ou estudos sobre a sala de aula são o foco desses escritos e nos convidam a pensar na especificidade das pesquisas realizadas no campo do ensino de História.

Nem todos os artigos (nos quatro volumes da RHHJ) que resultam de projetos de pesquisa explicitaram a pergunta e os objetivos da investigação, de forma que se pudesse analisar sua inserção no campo do ensino de História. Sabe-se não se tratar somente de pensar quais conceitos, metodologias ou espaço da pesquisa caracterizam esse campo. É necessário que a pergunta e os objetivos digam respeito ao ensino ou à aprendizagem da História. Em 1995, Selva Guimarães perguntava: qual é o objeto de estudo do ensino da História? Em 2007, Sonia Miranda responderia a essa pergunta evidenciando a complexidade do saber histórico escolar no "qual se entrecruzam culturas, sujeitos, instituições, tradições, relações, poderes, saberes, aprendizagens, fracassos e sucessos" (MIRANDA, 2007, p. 38).

A análise das publicações dos quatro volumes da RHHJ, buscando a presença/ausência da sala de aula foi uma tentativa de encontrar pistas de que houve avanço em relação às tensões do campo do ensino de História, principalmente àquela relacionada à divisão ensino e pesquisa. Arrisca-se dizer que os pesquisadores superaram a perspectiva de que "para ensinar História basta saber os conteúdos" ou, em outro extremo, "para ensinar História basta saber ensinar". A presença de um artigo da pesquisadora uruguaia Ana Zavala em um dos dossiês tem relevância para estimular o pensamento sobre as demandas básicas do ensino de História: é preciso saber os conteúdos, saber ensinar e saber teorizar sobre o que se ensina. Cristiani lembra que as pesquisas do Mestrado Profissional em Ensino de História (ProfHistória) mostram a possibilidade de construir conhecimento investigando as práticas concernentes à sala de aula. Essa produção precisa estar mais presente nas publicações da RHHJ. 
A produção de conhecimento na RHHJ ajuda a formular perguntas sobre o campo do ensino de História e, quem sabe, construir uma pauta de pesquisas: qual a relevância de historicizar a prática de sala de aula e não só a História como disciplina? Se o ensino de História é de fato um campo de pesquisa, qual sua epistemologia? Os artigos aceitos e publicados nas seções História Hoje na Sala de Aula e Falando de História Hoje contribuíram ou não para o debate do ensino de História? Essa produção atende aos objetivos das respectivas seções? A sala de aula está em evidência? Como operar, nas pesquisas, com reformas curriculares focadas em competências e habilidades e outras que promoveram a inclusão da história e da cultura africanas, afro-brasileiras e indígenas? Que história ensinar na educação básica para fortalecer a democracia, ampliar a participação e promover justiça social? Como ensinar história em diálogo com os direitos humanos no ambiente digital? Investigar a sala de aula com atenção aos sujeitos que nela circulam todos os dias implica colocar acento no/a professor/a? Qual o lugar das crianças e jovens nos estudos que se voltam para a sala de aula de História? Como as pesquisas desenvolvidas por professores/as do ProfHistória podem ampliar a perspectiva sobre a sala de aula observada desde dentro? Finalmente, fica a pergunta aos pesquisadores e pesquisadoras do ensino de História a respeito dos dados fornecidos pelo texto de Oldimar Cardoso et al.: o que as palavras em estabilidade - "história", "ensino" e "poder" - anunciam sobre a produção de conhecimento em ensino de História de 2012 a 2020 na RHHJ? Seguimos em diálogo!

\section{FONTES}

SILVA, Cristiani Bereta da. Editorial. Revista História Hoje, v. 4, n. 8, p. 07-08, 2015.

SILVA, Cristiani Bereta da. Editorial. Revista História Hoje, v. 5, n. 9, p. 01-04, 2016.

SILVA, Cristiani Bereta da. Editorial. Revista História Hoje, v. 5, n. 10, p. 01-04, $2016 \mathrm{~b}$.

SILVA, Cristiani Bereta da. Editorial. Revista História Hoje, v. 6, n. 11, p. 01-02, 2017.

SILVA, Critiani Bereta. A Editoria na RHHJ. Entrevista concedida a Carmem Zeli de Vargas Gil em março de 2021. 


\section{REFERENNCIAS}

ALEM, Nathalia Helena; PEREIRA, Júnia Sales. Ensinar História no ensino médio integrado à Educação Técnica Profissional: muitas questões, grandes desafios. Revista História Hoje, v. 5, n. 10, p. 46-65, 2016.

ALMEIDA, Leandro Antonio. Produção de livros didáticos no mestrado profissional de História: relato de experiência a partir de uma disciplina da UFRB. Revista História Hoje, v. 5, n. 9, p. 221-248, 2016.

ALVES, Luis Alberto. Epistemologia e Ensino da História. Revista História Hoje, v. 5, n. 9, p. 131-158, 2016.

AZEVEDO, Patricia Bastos de. História Ensinada e Dialogismo: prática de letramento no $6^{\circ}$ ano do Ensino Fundamental. Revista História Hoje, v. 4, n. 8, p. 15-31, 2015.

AZAMBUJA, Luciano de. Canção, ensino e aprendizagem histórica. Revista História Hoje, vol. 6, n. 11, 2017.

CAIMI, Flavia; MISTURA, Letícia. Investigar em Ensino de História: entre fronteiras e desafios epistemológicos. MONTEIRO, Ana Maria; RALEJO, Adriana. Cartografias da Pesquisa em Ensino de História. Rio de Janeiro: Mauad, 2019, p. 187-198.

CARDOSO, Oldimar Pontes; COSTA, Marco Aurélio da; FARIAS, Waleska Maria Lopes; MARTINS, Gustavo Ítalo Freire; SILVA, João Carlos de Melo. Comparação de megadados das duas revistas da Anpuh ou Introdução à ciência aberta para historiadores. Revista História Hoje, Edição Especial, jul. 2021, p. 134-155.

COELHO, Mauro Cezar; BICHARA, Taissa. Ensino de História: uma incursão pelo campo. In: MONTEIRO, Ana Maria; RALEJO, Adriana. Cartografias da Pesquisa em Ensino de História. Rio de Janeiro: Mauad, 2019, p.64-84.

COSTA, Aryane; OLIVEIRA, Margarida. O ensino de história como objeto de pesquisa no Brasil: no aniversário de 50 anos de uma área de pesquisa, notícias do que virá. Revista Saeculum. UFPB, 2007.

CUESTA, Virginia. Enseñanza de la Historia y enfoque narrativo. Revista História Hoje, v. 4, n. 8, p. 152-173, 2015.

DUQUE, Luís Guilherme Ritta. Na trilha sonora da História: a canção brasileira como recurso didático-pedagógico na sala de aula. Revista História Hoje, v. 6, n. 11, p. 295-314, 2017.

GABRIEL, Carmen Teresa. Jogos do tempo e processos de identificação hegemonizados nos textos curriculares de História. Revista História Hoje, v. 4, n. 8, p. 32-56, 2015.

GAGO, Marília. Consciência Histórica e narrativa no ensino da História: Lições da 
História...? Ideias de professores e alunos de Portugal. Revista História Hoje, v. 5, n. 9, p. 76-93, 2016.

GATTI JÚNIOR, Décio. Uma experiência de formação de Professores em torno do conhecimento histórico-educacional na Universidade Federal de Uberlândia. Revista História Hoje, v. 4, n. 8, p. 288-314, 2015.

FONTINELES, Claudia Cristina da Silva. As "centelhas da esperança": o papel da literatura e da música no despertar da consciência histórica. Revista História Hoje, v. 5, n. 9, p. 131-158, 2016.

GUIMARÃES, Selva; SILVA, Marcos. La producción académica sobre la enseñanza de la Historia en Brasil (1993-2010): una cartografía. In: PLÁ, Sebastián; PAGĖS, Joan. La investigación en la enseñanza de la historia en América Latina. México D.F.: Universidad Pedagógica Nacional (UPN) y Bonilla Artigas Editores, 2014, p.71-86.

MANIFESTO do Piaraçu - das lideranças indígenas e caciques do Brasil. Aldeia Piaraçu, janeiro de 2020.

MARTINS, Bruno Viveiros. Decantando a República: um encontro entre o historiador e o compositor popular. Revista História Hoje, v. 6, n. 11, p. 57-77, 2017.

MELLO, Ricardo Marques de. As três durações de Fernand Braudel no Ensino de História: proposta de atividade. Revista História Hoje, v. 6, n. 11, p. 237-254, 2017.

MESQUITA, Ilka Miglio. Urdidura e Trama de memórias do ensino de História. Aracaju: EDUNIT, 2017.

MIRANDA, Sonia. A pesquisa em Ensino de História no Brasil: potência e vicissitudes de uma comunidade disciplinar. In: MONTEIRO, Ana Maria; RALEJO, Adriana. Cartografia da pesquisa em ensino de História. Rio de Janeiro: Mauad, 2019, p. 85112.

MISTURA, Letícia; CAIMI, Flavia. O Ensino de História no Brasil e seus pesquisadores: breves notas sobre uma herança de tensões e proposições. Escritas do Tempo, v. 2, n. 5, 2020, p. 92-116.

MONTEIRO, Ana Maria Ferreira da Costa; AMORIM, Mariana de Oliveira. Potencialidades das "narrativas de si" em narrativas da História escolar Potencialities. Revista História Hoje, v. 4, n. 8, p. 15-31, 2015.

OLIVEIRA, Itamar Freitas de; OLIVEIRA, Margarida Maria Dias de. História Hoje: duas décadas. Revista História Hoje, Edição Especial, jul. 2021, p. 9-34.

ROLO, Clauidia; PEREIRA, Pedro Teixeira. Flipped classroom em História e Geografia de Portugal: contributos de um estudo numa turma do $5^{\circ}$ ano. Revista História Hoje, v. 6, n. 11, p. 272-294, 2017.

SADDI, Rafael. O Estado de Suspensão na aprendizagem histórica: a força estética do 
conhecimento histórico na instauração de um momento sublime de consciência histórica. Revista História Hoje, v. 5, n. 9, p. 131-158, 2016.

SILVA, Flavia Jovelino. Ditadura militar sob o olhar de composições musicais. Revista História Hoje, v. 6, n. 11, p. 255-271, 2017 b.

SOARES, Olavo Pereira; HERMETO, Miriam. Apresentação do Dossiê Música e Ensino de História. Revista História Hoje, vol. 6, n. 11, 2017.

TONON, Eloy; LIMA, Soeli Regina. Guerra do Contestado e ensino de História: sobre os ataques de sertanejos no município de Canoinhas (1914-1916). Revista História Hoje, v. 5, n. 10, p. 180-202, 2016.

ZAMBONI, Ernesta; LUCINI, Marizete; MIRANDA, Sonia. O saber histórico escolar e a tarefa educativa na contemporaneidade. In: SILVA, Marcos (org.). História: que ensino é esse? Campinas: Papirus, 2013, p. 253-276.

ZAMBONI, Ernesta. Panorama das pesquisas no ensino de História. Saeculum, Revista de História, n. 6/7, jan.-dez. 2000/2001.

ZAVALA, Ana. La investigación práctica de la práctica de la enseñanza. Clío \& Asociados. La Historia Enseñada, n. 12, 2008. p. 241-271.

ZAVALA, Ana. Historia de un gesto inacabado - Lecturas a contrapelo en torno a la emancipación de los docentes. Revista Encuentros Uruguayos, v. IX, n. 2, dez. 2016, p. 109-126.

\section{NOTAS}

${ }^{1}$ A entrevista, realizada especificamente para a escrita deste texto, ocorreu em março em dois momentos: primeiro enviei a ela as perguntas por e-mail e, após 20 dias, agendamos uma conversa sobre as perguntas. Logo após, ela enviou, por e-mail, as perguntas respondidas.

${ }^{2}$ Cabe destacar que os textos dos editoriais seguem uma mesma estrutura, ou seja, iniciam com os assuntos que mobilizam o campo do ensino de História e a educação em geral; na segunda parte, a editora reafirma o compromisso da RHHJ engajando-se nas lutas educacionais e, por fim, apresenta o dossiê, destacando a relevância de seu tema para o ensino da História, tal como escreve no dossiê Música e ensino de História: "[...] em diferentes lugares e tempos a música foi/é usada como instrumento político, ferramenta de contestação, de resistência" (SILVA, 2017, p. 2).

${ }^{3}$ Considero aqui temas clássicos como aqueles localizados nas pesquisas em ensino de História desde final dos anos 80 , entre eles formação de professores, livros didáticos, metodologias etc.

${ }^{4}$ Entre esses está a obra de Lawrence Stenhouse que, em 1975, propôs pesquisas em con- 
junto reunindo professores e pesquisadores externos à escola, ou Donald Schön, que, em 1983, falava do professor reflexivo, inspirando-se em John Dewey.

${ }^{5}$ Em seu texto neste dossiê, Oldimar Cardoso e os autores/as que o acompanham, anunciam que o "artigo funciona como uma introdução à ciência aberta para historiadores". E, de início, propõem a questão: "Por que precisamos de uma história aberta?".

${ }^{6}$ No artigo de Oldimar Cardoso et al. neste dossiê, a Tabela 3 evidencia o conjunto das palavras que aparecem, assim como a explicação sobre a construção da mesma.

${ }^{7} \mathrm{O}$ uso dessa classificação é explicada no artigo de Oldimar Cardoso et al., apresentado neste dossiê, na Tabela 4, onde conta que "para classificar cada palavra diante dos fenômenos de ascensão (a palavra passa a ser cada vez mais usada nos corpora de cada período), queda (a palavra passa a ser cada vez menos usada nos corpora de cada período), estabilidade (a palavra é usada em quantidades próximas nos corpora de todos os períodos), ascensão repentina (a palavra já estava entre as mais usadas nos primeiros períodos e passa a ser ainda mais usada nos últimos períodos) e aparecimento repentino (a palavra sequer estava entre as mais usadas nos primeiros períodos, mas aparece entre elas nos últimos períodos)".

Artigo submetido no dia 18 de maio de 2021. 